\title{
Anatomia dos órgãos vegetativos de Cactaceae da caatinga pernambucana ${ }^{1}$
}

\author{
EMILIA ARRUDA ${ }^{2,4}$, GLADYS FLÁVIA MELO-DE-PINNA² e MARCCUS ALVES ${ }^{3}$
}

(recebido: 4 de março de 2004; aceito: 25 de agosto de 2005)

\begin{abstract}
Anatomy of the vegetative organs of Cactaceae of the caatinga from Pernambuco). Root and cladode transections of five species of Cactaceae from a "caatinga" of Pernambuco (Harrisia adscendens (Gürke) Britton \& Rose; Melocactus $\times$ horridus Wedermann; M. zenhtneri (Britton \& Rose) Luetzelb.; Tacinga inamoena (Schumann) Taylor \& Stuppy, and T. palmadora (Britton \& Rose) Taylor \& Stuppy), were analyzed to verify diagnostic and adaptative features. The sections were stained with safranin and astrablue and mounted in glycerine. The surveys did not show great differences in the roots inner structure among studied species. In the secondary xylem of the roots broad pericyclic rays occur, representing an important adaptative character in xerophytes. The cladodes present the following diagnostic and adaptative features: type of spines; type and position of stomata; hypodermis structure; presence of crystals in epidermis and hypodermis; type and position of mucilaginous structures; general aspects of the vascular system; occurrence of cortical and medular vascular bundles; and presence of storage parenchyma. The results of this work show that the studied species are typical cacti presenting anatomical features, which can be responsible for the success of these plants in adverse environments as the "caatinga".
\end{abstract}

Key words - anatomy, caatinga, Cactaceae, taxonomy

RESUMO - (Anatomia dos órgãos vegetativos de Cactaceae da caatinga pernambucana). Secções de raízes e cladódios de cinco espécies de Cactaceae ocorrentes em uma região de caatinga de Pernambuco (Harrisia adscendens (Gürke) Britton \& Rose; Melocactus $\times$ horridus Wedermann Notizbl.; M. zenhtneri (Britton \& Rose) Luetzelb.; Tacinga inamoena (Schumann) Taylor \& Stuppy e T. palmadora (Britton \& Rose) Taylor \& Stuppy), foram analisadas para verificação de caracteres diagnósticos e adaptativos. As secções foram coradas com safranina e azul de astra e montadas em glicerina. As observações feitas mostraram que a estrutura interna das raízes é bastante similar não sendo observados caracteres diagnósticos. No xilema secundário das raízes ocorrem amplos raios pericíclicos representando um importante caracter adaptativo. O cladódio apresenta os seguintes caracteres diagnósticos e adaptativos: tipos de espinho; tipo e posição dos estômatos; estrutura da hipoderme; tipo e posição das estruturas mucilaginosas; aspecto geral do sistema vascular; ocorrência de feixes corticais e medulares; presença de cristais na epiderme e hipoderme e presença de parênquima aqüífero. Os resultados deste trabalho mostram que as espécies estudadas são cactos típicos apresentando caracteres, que podem ser responsáveis pelo sucesso destas plantas em ambientes adversos como a caatinga.

Palavras-chave - anatomia, caatinga, Cactaceae, taxonomia

\section{Introdução}

A família Cactaceae apresenta aproximadamente 125 gêneros e 1.900 espécies (Areces 2004), ocorrendo nas regiões tropicais e temperadas do continente americano e encontra-se distribuída em uma ampla variedade de hábitats, desde regiões áridas até

1. Parte do Trabalho de Conclusão de Curso em Bacharelado da primeira autora, pela Universidade Federal de Pernambuco.

2. Universidade de São Paulo, Instituto de Biociências, Departamento de Botânica, Rua do Matão, Travessa 14, 05422-970 São Paulo, SP, Brasil.

3. Universidade Federal de Pernambuco, Centro de Ciências Biológicas, Departamento de Botânica, Av. Prof. Moraes Rego s/n, 50372-970 Recife, PE, Brasil.

4. Autor para correspondência: emilia.arruda@bol.com.br florestas úmidas (Hunt \& Taylor 1990). No Brasil, estão registradas 160 espécies pertencentes a 32 gêneros (Barroso et al. 1978), dentre as quais 80, subordinadas a 18 desses gêneros, ocorrem na região Nordeste (Barbosa et al. 1996). Segundo Rizzini (1987), as espécies de Cactaceae que ocorrem no Brasil podem ser classificadas em cinco grupos, de acordo com o seu hábitat: 1) silvícolas - que habitam florestas pluviais: amazônica e atlântica, com predominância de espécies epífitas; 2) savanícolas - no cerrado; 3) campestres - em campos rupestres de Minas Gerais; 4) litorâneas - no litoral brasileiro; 5) xerófilas - bioma caatinga, abrangendo maior número de espécies.

A família encontra-se subdividida em três subfamílias Pereskioideae, Opuntioidae e Cactoideae (Barthlott \& Hunt 1993), sendo recentemente proposta 
uma nova subfamília, Mahiuenioideae, à qual foi subordinado o gênero Mahiuenia (Weber) Schumann, antes pertencente à subfamília Pereskioideae (Anderson 2001).

Vários trabalhos foram realizados utilizando a morfologia como importante ferramenta na taxonomia da família, entre eles Britton \& Rose (1937), Zappi (1994), Taylor (2000) e Rocha \& Agra (2002). Por sua vez, alguns aspectos anatômicos têm-se revelado úteis em termos diagnósticos, como padrão de espessamento das paredes celulares da hipoderme, tipo de espinhos ocorrente nas aréolas, ocorrência de feixes vasculares corticais e medulares, tipo e localização de estruturas secretoras (Conde 1975, Mauseth 1989, 1999, Silva \& Alves 1999, Soffiatti \& Angyalossy 2003).

Por ser uma família cujos representantes ocorrem, predominantemente, em regiões áridas, alguns caracteres podem ser interpretados como adaptativos (Gibson 1973, Mauseth \& Ross 1988, Sajeva \& Mauseth 1991, Mauseth \& Sajeva 1992, Mauseth 1993a, b, Mauseth \& Plesmons-Rodriquez 1998, Soffiatti \& Angyalossy 2003).

No Brasil poucos são os trabalhos anatômicos e morfológicos desenvolvidos sobre a família, especialmente no que diz respeito à região Nordeste. Entre esses trabalhos podem ser mencionados os de Silva \& Alves (1999) com espécies de Pilosocereus Byles \& Rowley ocorrentes no Estado de Pernambuco; Soffiatti \& Angyalossy (2003) abordando aspectos da anatomia do caule de espécies de Cypocereus Ritter da Cadeia do Espinhaço e Arruda et al. (2004) analisando elementos traqueais em espécies ocorrentes na caatinga pernambucana.

Com o objetivo de apontar caracteres que possam auxiliar na diagnose, bem como no entendimento das adaptações destas plantas ao ambiente, este trabalho apresenta a análise morfoanatômica dos órgãos vegetativos de Cactaceae ocorrentes em um trecho de caatinga do estado de Pernambuco.

\section{Material e métodos}

Foram estudadas raízes e cladódios de indivíduos de Harrisia adscendens (Gürke) Britton \& Rose; Melocactus $\times$ horridus Wedermann Notizbl.; Melocactus zehntneri (Britton \& Rose) Luetzelb.; Tacinga inamoena (Schumann) Taylor \& Stuppy e Tacinga palmadora (Britton \& Rose) Taylor \& Stuppy. O material analisado é proveniente das Fazendas Cajueiro Seco e Lagoa Seca, localizadas no Município de Alagoinha, $08^{\circ} 29^{\prime \prime} \mathrm{S}$ e $36^{\circ} 47^{\prime}$ W, cerca de $780 \mathrm{msm}$ (FIAM 1994), em um trecho de caatinga do estado de Pernambuco, no limite entre o Agreste e o Sertão Central, segundo a classificação proposta por Andrade-Lima (1960). Material testemunho foi depositado no Herbário - UFP do Departamento de Botânica da Universidade Federal de Pernambuco (tabela 1).

Parte do material vegetativo coletado foi fixado em FAA50\% (Johansen 1940) e posteriormente conservado em etanol 70\% (Sass 1951). A partir deste material, foram realizadas secções transversais e longitudinais à mão livre, com auxílio de lâmina de barbear (Johansen 1940), e as secções foram submetidas à dupla coloração com azul de astra e fucsina básica, seguindo metodologia descrita por Kraus et al. (1998).

Testes microquímicos foram realizados utilizando os seguintes reagentes: Sudan III (Sass 1951), cloreto férrico (Johansen 1940) e lugol (Berlyn \& Miksche 1976), para detecção de substâncias lipídicas, substâncias fenólicas e amido, respectivamente.

A epiderme dos cladódios foi analisada através de: 1) Dissociação com solução de ácido acético e peróxido de hidrogênio $1: 1$, seguida de coloração com safranina $1 \%$ em etanol 50\% (Franklin 1945) e montagem em glicerina 50\% (Purvis et al. 1964); 2) Microscopia eletrônica de varredura (MEV) em Microscópio Zeiss DSM 940, sendo as amostras submetidas à desidratação em série etílica e ao ponto crítico com gás carbônico (CPD 030, Balzer) e o material depois de seco aderido a suportes metálicos e posteriormente metalizado com ouro (Silveira 1989).

Diagramas esquemáticos de cladódio e espinhos foram confeccionados com auxílio de câmara clara acoplada ao microscópio óptico. As escalas foram feitas com auxílio de lâmina milimetrada, projetada nas mesmas condições ópticas.

Tabela 1. Lista dos indivíduos estudados com número de coletor e origem.

Table 1. List of the individuals studied with collector number and origin.

\begin{tabular}{lll}
\hline Indivíduos estudados & Coletor & Localidade \\
\hline Harrisia adcendens (Gürke) Britton \& Rose & E. Arruda 8 & Alagoinha, PE \\
Melocactus $\times$ horridus Werdermann Notizbl. & E. Arruda 10 & Alagoinha, PE \\
Melocactus zehntneri (Britton \& Rose) Luetzelb. & E. Arruda 9 & Alagoinha, PE \\
Tacinga inamoena (Schumann) Taylor \& Stuppy & E. Arruda 7 & Alagoinha, PE \\
Tacinga palmadora (Britton \& Rose) Taylor \& Stuppy & E. Arruda 11 & Alagoinha, PE \\
\hline
\end{tabular}




\section{Resultados}

Os principais caracteres observados nos indivíduos analisados encontram-se resumidos na tabela 2.

Raiz - Nos indivíduos analisados, foram encontradas apenas raízes adventícias que surgem da base do hipocótilo, constituindo um sistema radicular fasciculado. O sistema de revestimento apresenta, em estrutura primária, a epiderme unisseriada de onde partem pêlos unicelulares (figura 1). Na região cortical, as células apresentam contorno arredondado e estão limitadas internamente pela endoderme (figura 2). Em estrutura secundária, o sistema de revestimento é composto pela periderme, cujas células das camadas externas apresentam paredes lignificadas (figuras 3,4). Nesta fase, a estrutura interna das raízes está constituída pela periderme e pelo sistema vascular, tendo sido eliminada praticamente quase toda a região cortical, como pode ser visto em Melocactus $\times$ horridus Wedermann Notizbl. (figura 4).

O sistema vascular se encontra delimitado externamente pelo periciclo, o qual é multisseriado. $\mathrm{O}$ floema primário apresenta-se colapsado, sendo visualizadas apenas as células do floema secundário (figura 4).

$\mathrm{O}$ xilema de todos os indivíduos analisados nesse estágio está constituído por elementos de vaso, com diâmetros variáveis, que ocorrem isolados ou agrupados, além de numerosas fibras e parênquima escasso ou ausente (figura 4). Foram observados raios, os quais em secção transversal apresentam 2-4 fileiras de células (figuras 3,4). Nas células do raio observam-se drusas e amiloplastos em todos os indivíduos, exceto em Harrisia adscendens (Gürke) Britton \& Rose. Cladódio - Através dos diagramas representativos de secções transversais dos cladódios são evidenciadas diferenças no aspecto geral do órgão (figura $5 \mathrm{~A}-\mathrm{C}$ ).

O sistema de revestimento do cladódio, em secção transversal, apresenta epiderme unisseriada, a qual é levemente ondulada em Harrisia adscendens (figura 6), e Tacinga inamoena (Schumann) Taylor \& Stuppy, fortemente ondulada como T. palmadora (Britton \& Rose) Taylor \& Stuppy (figuras 7, 8) ou plana em Melocactus $\times$ horridus e M. zehntneri (Britton \& Rose) Leuetzelb. (figura 9). Em Melocactus, $H$. adscendens e T. inamoena os estômatos estão

Tabela 2. Principais caracteres anatômicos de raízes e cladódios dos indivíduos estudados $(\mathrm{S}=$ presente; $\mathrm{N}=$ ausente $)$.

Table 2. Means anatomical characters of roots and cladodes of the individuals studied $(\mathrm{S}=$ present; $\mathrm{N}=\mathrm{absent})$.

\begin{tabular}{|c|c|c|c|c|c|}
\hline Caracteres & $\begin{array}{l}\text { Harrisia } \\
\text { adscendens }\end{array}$ & $\begin{array}{c}\text { Melocactus } \times \\
\text { horridus }\end{array}$ & M. zehtneri & $\begin{array}{l}\text { Tacinga } \\
\text { inamoena }\end{array}$ & T. palmadora \\
\hline Tipo de espinho & liso & $\begin{array}{l}\text { com projeções } \\
\text { celulares }\end{array}$ & $\begin{array}{l}\text { com projeções } \\
\text { celulares }\end{array}$ & $\begin{array}{c}\text { liso e } \\
\text { gloquídeo }\end{array}$ & liso e gloquídeo \\
\hline Tipo de estômato & paralelocítico & paralelocítico & paralelocítico & hexacítico & hexacítico \\
\hline $\begin{array}{l}\text { Localização do estômato } \\
\text { em relação às demais } \\
\text { células epidérmicas } \\
\text { (vista transversal) }\end{array}$ & mesmo nível & mesmo nível & mesmo nível & mesmo nível & acima \\
\hline $\begin{array}{l}\text { Parede anticlinal das } \\
\text { células epidérmicas } \\
\text { (vista frontal) }\end{array}$ & retas & sinuosas & sinuosas & sinuosas & sinuosas \\
\hline Epiderme (vista transversal) & $\begin{array}{l}\text { levemente } \\
\text { ondulada }\end{array}$ & plana & plana & $\begin{array}{l}\text { levemente } \\
\text { ondulada }\end{array}$ & $\begin{array}{l}\text { fortemente } \\
\text { ondulada }\end{array}$ \\
\hline Cristais na epi e hipoderme & $\mathrm{N}$ & $\mathrm{S}$ & $\mathrm{S}$ & $\mathrm{S}$ & S \\
\hline Lume das células da hipoderme & regular & irregular & irregular & regular & regular \\
\hline Tipo de estrutura secretora & células & células & células & canais & canais \\
\hline Localização da estrutura secretora & córtex e medula & córtex e medula & córtex e medula & córtex & córtex \\
\hline Feixes corticais & $\mathrm{S}$ & $\mathrm{S}$ & $\mathrm{S}$ & $\mathrm{N}$ & $\mathrm{N}$ \\
\hline Feixes medulares & $S$ & $S$ & $S$ & $\mathrm{~N}$ & $\mathrm{~N}$ \\
\hline $\begin{array}{l}\text { Predomínio de células } \\
\text { parenquimáticas no xilema }\end{array}$ & $\mathrm{N}$ & $S$ & $S$ & $S$ & $\mathrm{~S}$ \\
\hline
\end{tabular}



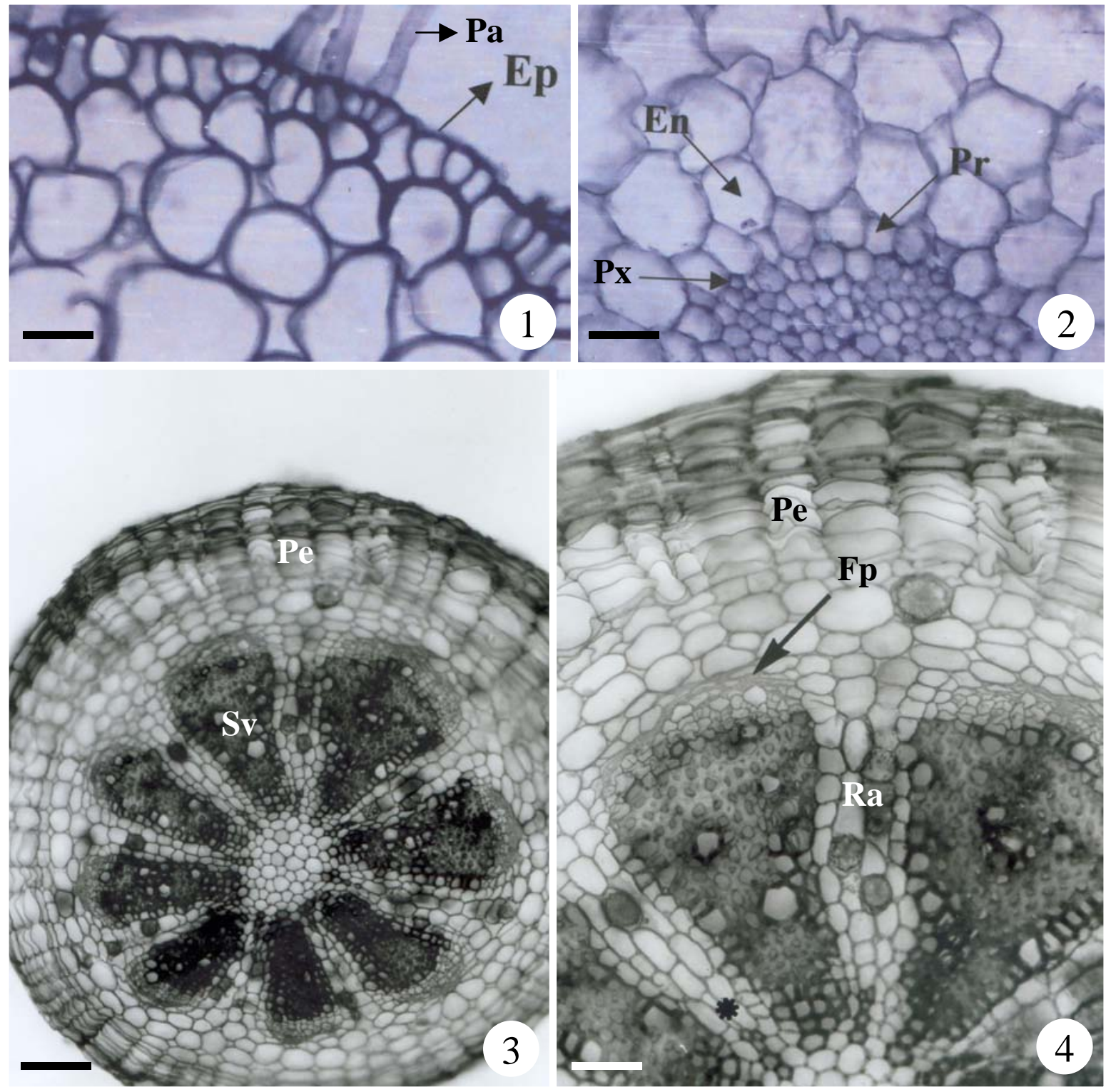

Figuras 1-4. Secções transversais de raízes em estágio primário de desenvolvimento (1-2) e em crescimento secundário (3-4). 1-2: Tacinga palmadora. 1. Células epidérmicas (Ep) e pêlos absorventes (Pa). 2. Detalhes da região cortical interna e do sistema vascular, assinalam-se células do protoxilema (Px), a endoderme (En) e periciclo (Pr). 3-4: Tacinga inamoena. 3. Aspecto geral, mostrando a organização do sistema de revestimento (Pe) e vascular (Sv). 4. Detalhe da figura anterior, evidenciando a periderme ( $\mathrm{Pe}$ ) e o sistema vascular; estão assinalados o floema primário colapsado (seta, Fp), um pólo de protoxilema (asteristico) e um raio $(\mathrm{Ra}) .(\mathrm{En}=$ endoderme; $\mathrm{Ep}=$ epiderme; $\mathrm{Fp}=$ floema primário; $\mathrm{Pa}=$ pêlo absorvente; $\mathrm{Pe}=$ periderme; $\mathrm{Px}=$ protoxilema; $\mathrm{Pr}=$ periciclo; $\mathrm{Rm}=$ raio medular; $\mathrm{Sv}=$ sistema vascular). $\mathrm{Barra}=12,5 \mu \mathrm{m}(1,2) ; 100 \mu \mathrm{m}(3) ; 50 \mu \mathrm{m}$ (4).

Figures 1-4. Transversal sections of the roots in primary growth (1-2) and secondary growth (3-4). 1-2: Tacinga. Palmadora. 1. Epidermal cells (Ep) and roots hairs (Pa). 2. Details of the inner layers of the cortex and vascular system; the arrows show the protoxylem cells (Px), the endodermis (En) and pericycle (Pr). 3-4: Tacinga inamoena. 3. General view showing the organization of the dermal (Pr) and vascular systems (Sv). 4. Detail of the previous figure evidencing the peridermis (Pe) and the vascular system; the arrows show the primary phloem collapsed (arrow, Fp), one protoxylem groups (asterisks) and a ray (Ra). $(\mathrm{En}=$ endodermis $; \mathrm{Ep}=$ epidermis $; \mathrm{Fp}=$ primary phloem $; \mathrm{Pa}=$ roots hairs $; \mathrm{Pe}=$ peridermis $; \mathrm{Pr}=$ pericycle $; \mathrm{Px}=$ protoxylem; $\mathrm{Rm}=$ medullar ray; $\mathrm{Sv}=$ vascular system;). $\mathrm{Bar}=12,5 \mu \mathrm{m}(1,2) ; 100 \mu \mathrm{m}(3) ; 50 \mu \mathrm{m}(4)$. 


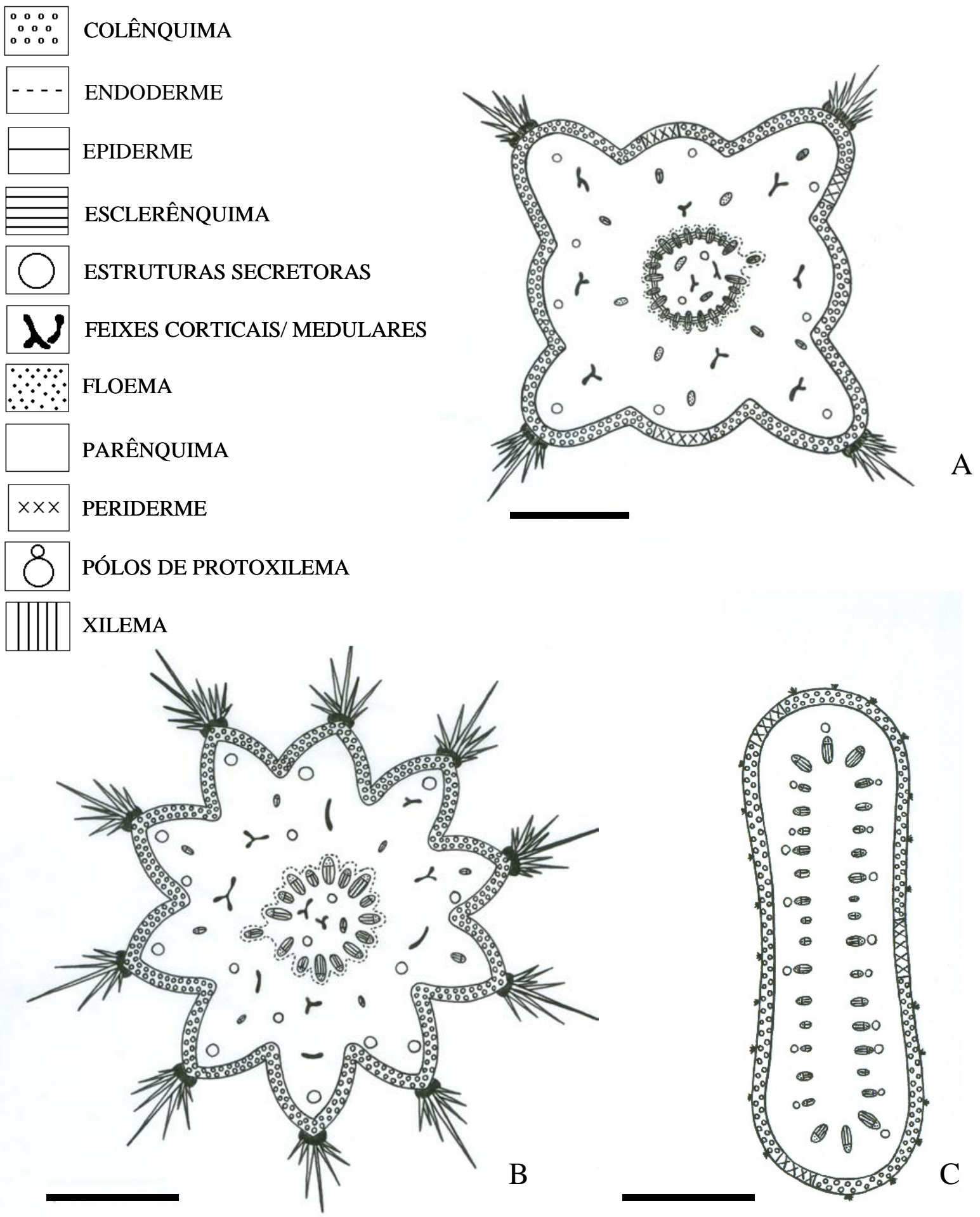

Figura 5A-C. Diagramas representativos da secção transversal dos cladódios. A. Harrisia adscendens. B. Melocactus $\times$ horridus. C. Tacinga inamoena. Barra $=0,5 \mathrm{~cm}(\mathrm{~A}) ; 4,5 \mathrm{~cm}(\mathrm{~B}) ; 1,2 \mathrm{~cm}(\mathrm{C})$.

Figure 5A-C. Representative diagrams of the transverse section of cladodes. A. Harrisia adscendens. B. Melocactus $\times$ horridus. C. Tacinga inamoena. $\mathrm{Bar}=0,5 \mathrm{~cm}(\mathrm{~A}) ; 4,5 \mathrm{~cm}(\mathrm{~B}) ; 1,2 \mathrm{~cm}(\mathrm{C})$. 
situados ao mesmo nível das demais células epidérmicas e em nível superior, em T. palmadora.

Em vista frontal foi possível observar os estômatos do tipo hexacítico (figura 10) em Tacinga e paralelocítico (figuras 11-13) em Melocactus e $H$. adscendens, além de distinções quanto ao aspecto das paredes anticlinais das células epidérmicas as quais são sinuosas em Tacinga e Melocactus (figuras 10, 11) e retas em $H$. adscendens (figura 12).
Na região das aréolas foram observados tricomas filiformes e multicelulares, além de espinhos em todos os indivíduos. Estes espinhos variam quanto ao tipo, podendo ser liso como observado em $H$. adscendens (figura 14A), do tipo gloquídeo em Tacinga, os quais apresentam células como "farpas" (figura 14B), ou com projeções irregulares em Melocactus (figura 14C).

Periderme descontínua foi observada em H. adscendens e T. palmadora, apresentando células
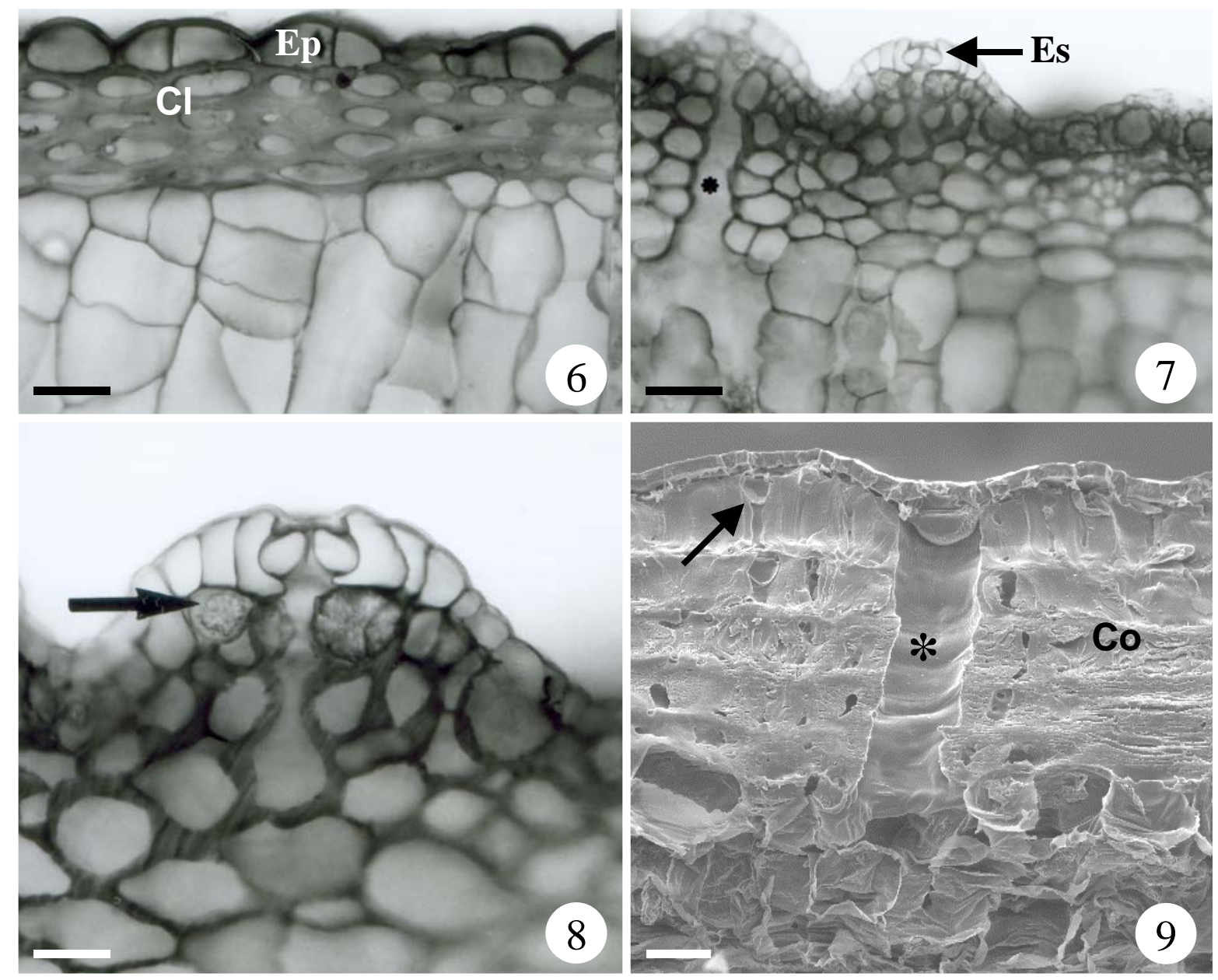

Figuras 6-9. Secções transversais dos cladódios. 6. Harrisia adscendens mostrando epiderme (Ep) e o colênquima lamelar (Cl). 7-8: Tacinga palmadora. 7. Epiderme ondulada; assinalam-se estômatos (Es) e uma câmara substomática (asterístico). 8. Detalhe da figura anterior, evidenciando célula da hipoderme com drusa (seta). 9. Secção transversal do cladódio de Melocactus zehntneri em MEV, mostrando epiderme plana e células colenquimáticas com lume irregular $(\mathrm{Co}) .(\mathrm{Cl}=$ colênquima lamelar; $\mathrm{Co}=$ colênquima; $\mathrm{Ep}=$ epiderme; Es = estômato). Barra $=20 \mu \mathrm{m}(6,7) ; 10 \mu \mathrm{m}(8) ; 20 \mu \mathrm{m}(9)$.

Figure 6-9. Transverse section of cladodes. 6. Harrisia adscendens showing epidermis (Ep) and lamellar collenchyma (Cl). 7-8. Tacinga palmadora. 7. Undulated surface; the arrows show stomata (Es) and substomatal chamber (asterisks). 8. Detail of the previous figure evidencing hypodermal cells with druses (arrow). 9. Scanning electron micrograph of transverse section of the cladodes of Melocactus zehntneri showing flattened surface and collenchyma cells with irregular lumen $(\mathrm{Co}) .(\mathrm{Cl}=$ lamellar collenchyma; $\mathrm{Co}=$ collenchyma; $\mathrm{Ep}=$ epidermis; $\mathrm{Es}=$ stomata). $\mathrm{Bar}=20 \mu \mathrm{m}(6,7) ; 10 \mu \mathrm{m}(8) ; 20 \mu \mathrm{m}(9)$. 
de paredes fortemente espessadas, embora na maior parte do órgão a epiderme ainda seja o tecido de revestimento predominante.

No sistema fundamental o colênquima subepidérmico apresenta diferenças quanto ao padrão de espessamento das paredes (figuras 6-9). Em $H$. adscendens foi observado colênquima lamelar com espessamento uniforme das paredes, ficando o lume celular circular (figura 6). Nos indivíduos de Tacinga o tipo de espessamento das células colenquimáticas tende a ser angular (figuras 7,8). Já em Melocactus o espessamento das paredes é irregular (figura 9). Grandes câmaras subestomáticas atravessam toda a extensão do colênquima subepidérmico (figuras 7-9). Nas regiões epidérmica e subepidérmica, foram detectadas drusas em Tacinga e cristais prismáticos em Melocactus. Cristais não foram observados em Harrisia adscendens (figura 6).

Ainda no sistema fundamental é possível notar, em todos os indivíduos analisados, que a região cortical compreende o parênquima clorofiliano (externo) e aqüífero (interno). Dos indivíduos analisados, apenas Tacinga não apresentou em toda a extensão do córtex e da medula, feixes vasculares colaterais, que são proporcionalmente menores que os do cilindro central (figura 15).
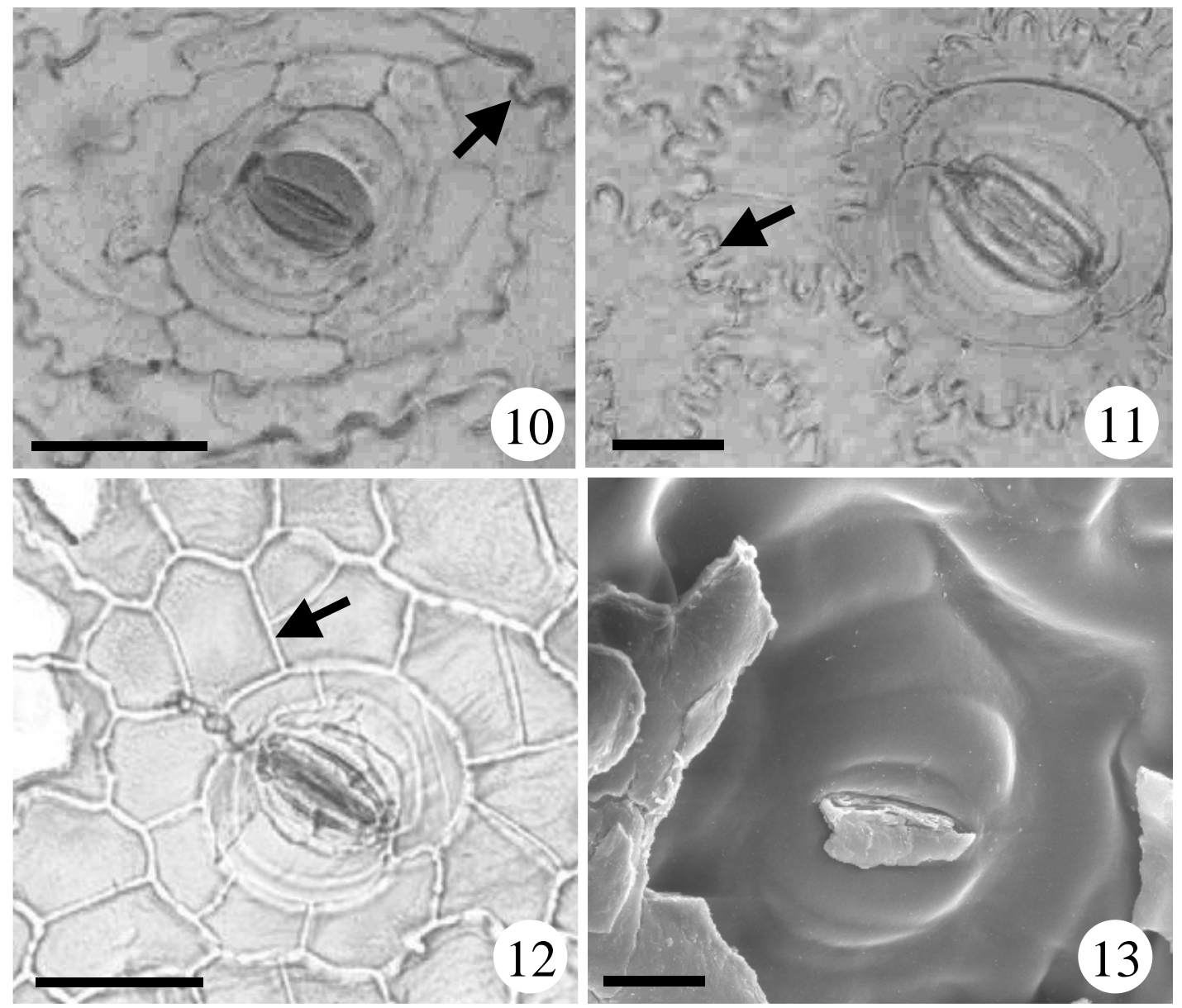

Figura 10-12. Vista frontal da epiderme do cladódio em microscopia óptica evidenciando estômatos e células epidérmicas. 10. Tacinga inamoena; mostrando estômato hexacítico e paredes celulares sinuosas (seta). 11-12: Estômatos paralelocíticos. 11. Melocactus zehntneri; assinalando-se as paredes celulares sinuosas. 12. Harrisia adscendens. Notar células com paredes retas (seta). 13. Melocactus $\times$ horridus; superfície do cladódio em MEV. Barra = $45 \mu \mathrm{m}(10) ; 25 \mu \mathrm{m}(11) ; 75 \mu \mathrm{m}(12) ; 10 \mu \mathrm{m}(13)$.

Figure 10-12. Surface view of the cladode in optic microscopie evidencing stomata and epidermal cells. 10. Tacinga inamoena; showing hexacytic stomata and sinuous cell walls (arrow). 11-12: Paralelocityc stomata. 11. Melocactus zehntneri; the arrow show the sinuous cell walls. 12. Harrisia adscendens; note the flattened cells walls (arrow). 13. Melocactus $\times$ horridus; view face of cladode in SEM. Bar $=45 \mu \mathrm{m}(10) ; 25 \mu \mathrm{m}(11) ; 75 \mu \mathrm{m}(12) ; 10 \mu \mathrm{m}$ (13). 
Foram detectadas células secretoras no córtex e na medula de $H$. adscendens, $M . \times$ horridus e M. zehntneri (figura 16); em Tacinga ocorrem canais secretores apenas na região cortical, os quais estão associados aos feixes vasculares, externamente ao floema primário (figuras 17, 18). Em todos os indivíduos estudados, drusas e amiloplastos estão presentes no sistema fundamental, exceto em $H$. adscendens.

O sistema vascular está constituído por feixes organizados em círculo. Nesses feixes, as células do floema primário se encontram colapsadas, e o floema secundário está constituído por elementos de tubo crivado e parênquima.

Com relação ao xilema, está constituído em $H$. adscendens (figuras 19, 20), essencialmente, por elementos de vaso e fibras, além de algumas células parenquimáticas. Já em Tacinga e Melocactus, foram detectados poucos elementos de vasos e fibras, estando o xilema formado principalmente por traqueídes vasculares e células parenquimáticas (figura 21). Essas traqueídes apresentam espessamento helicoidal de parede secundária (figura 22).
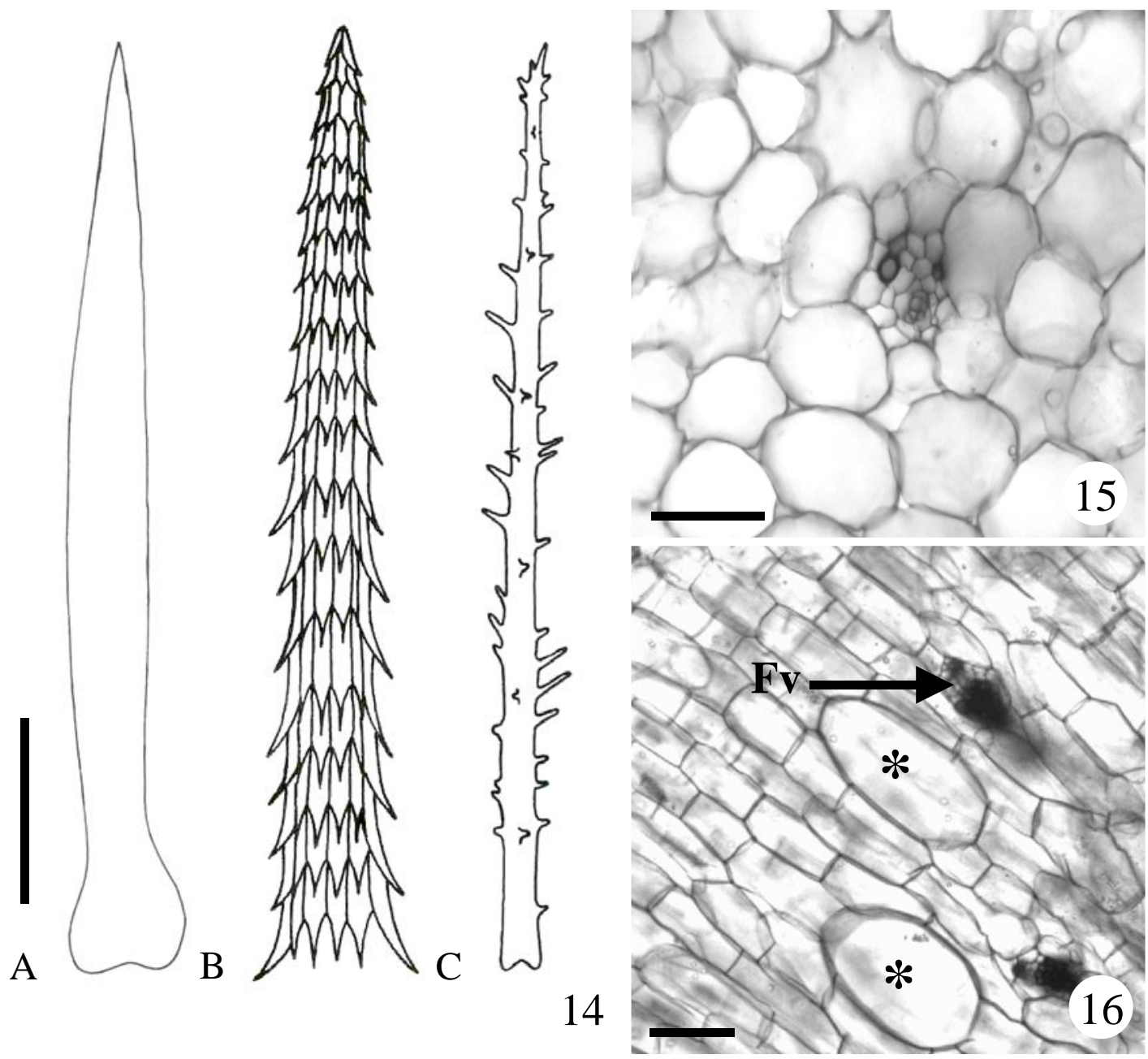

Figura 14A-C. Diagramas representativos de espinhos ocorrentes nas aréolas dos cladódios. A. Espinho liso de Harrisia adscendens. B. Gloquídeo de Tacinga. C. Espinho com projeções celulares irregulares de Melocactus. 15-16: Secção transversal do cladódio de Harrisia adscendens. 15. Detalhe de um feixe vascular cortical. 16. Região cortical evidenciando as células de mucilagem (*) e os feixes vasculares (Fv). (Fv = feixe vascular). Barra =200 $\mu \mathrm{m}(14) ; 50 \mu \mathrm{m}(15) ; 150 \mu \mathrm{m}(16)$.

Figure 14A-C. Representative diagrams of spines in the areoles of the cladodes. A. Spine of Harrisia adscendens. B. Glochids of Tacinga. C. Spine with irregular cellular projections of Melocactus. 15-16: Transversal section of the cladode of Harrisia adscendens. 15. Detail of one cortical vascular bundles. 16. Cortical region showing mucilage cells (*) and the vascular bundles (Fv). Bar $=200 \mu \mathrm{m}$ (14); $50 \mu \mathrm{m}$ (15); $150 \mu \mathrm{m}$ (16). 

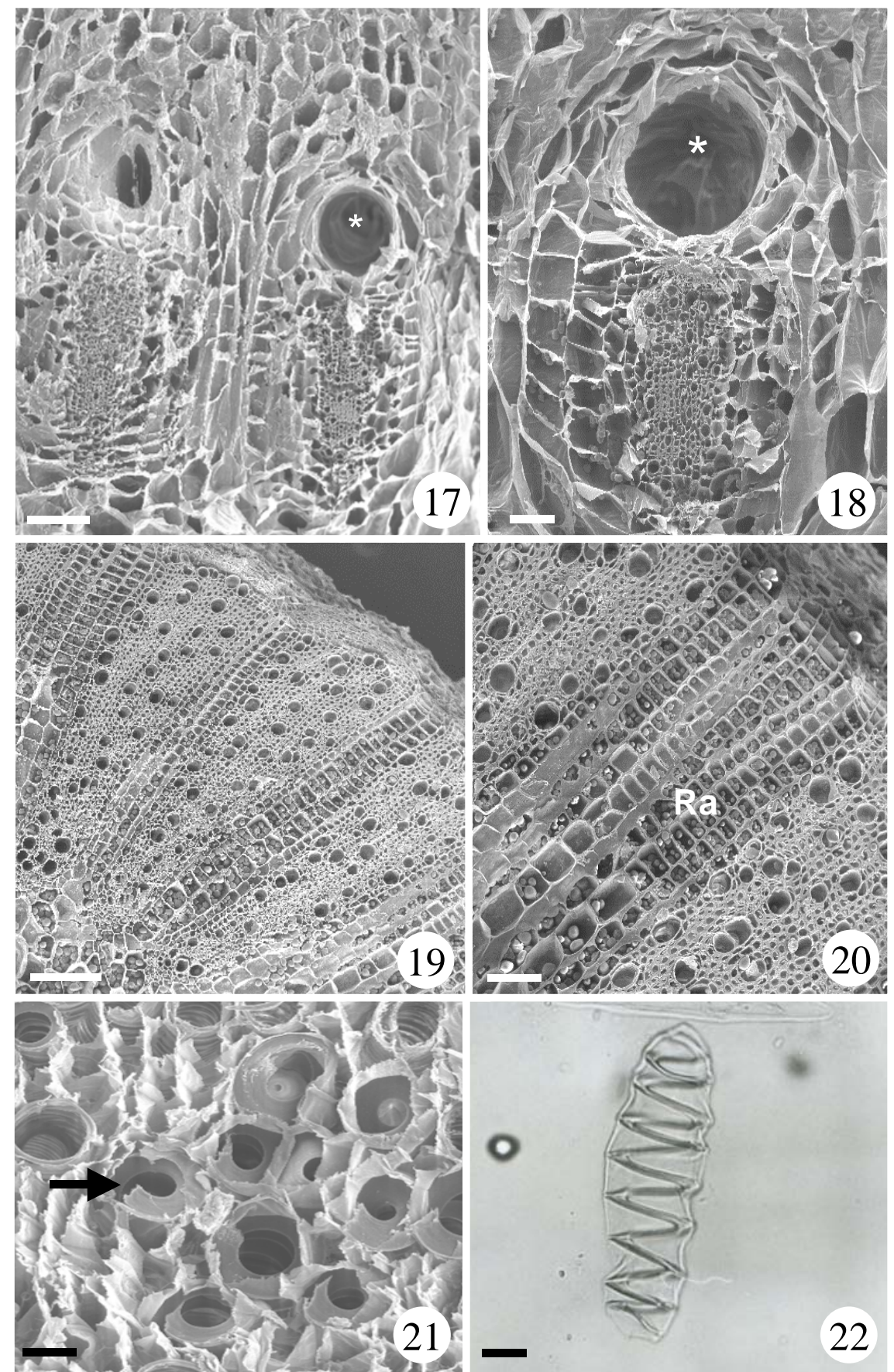

Figura 17-18. Secções transversais do cladódio de Tacinga inamoena em MEV. 17. Aspecto geral, mostrando a organização do xilema axial. 18. Detalhe da figura anterior, evidenciando o canal secretor de mucilagem (*). 19-20: Secção transversal do cladódio de Harrisia adscendens em MEV. 19. Organização do sistema vascular e células radiais. 20. Detalhe da figura anterior; assinalam-se as células raio (Ra). 21. Secção transversal do cladódio de Melocactus zehntneri em MEV, evidenciando as traqueídes vasculares (seta). 22. Traqueíde vascular obtida a partir do material macerado. Notar espessamento helicoidal. Barra $=200 \mu \mathrm{m}(17) ; 100 \mu \mathrm{m}(18) ; 200 \mu \mathrm{m}(19) ; 100 \mu \mathrm{m}(20) ; 50 \mu \mathrm{m}(21,22)$.

Figure 17-18. Transversal sections of cladode of Tacinga inamoena in SEM. 17. General aspects showing organization of the axial xylem. 18. Details of the previous figure, evidencing the secretory canal (*). 19-20: Scanning electron micrograph of the transversal sections of cladode of Harrisia adscendens. 19. Organization of the vascular system and rays. 20. Details of the previous figure, showing rays cells (Ra). 21. Transversal section of cladode of Melocactus zehntneri in SEM, evidencing the wide-band tracheid (arrow). 22. Wide-band tracheids obtained from a macerated material. Note helical thickening. Bar $=200 \mu \mathrm{m}$ (17); $100 \mu \mathrm{m}$ (18); $200 \mu \mathrm{m}$ (19); $100 \mu \mathrm{m}(20) ; 50 \mu \mathrm{m}(21,22)$. 
Apenas em $H$. adscendens foi observado que o sistema radial é constituído por células de paredes lignificadas (figuras 19, 20). Nos demais indivíduos esse sistema não está evidente ou, se presente, é integrado por células parenquimáticas não lignificadas, como em Tacinga inamoena (figura 17).

\section{Discussão}

A estrutura interna das raízes em estágio secundário apresenta-se semelhante entre os indivíduos analisados. Raios parenquimáticos provenientes da atividade cambial foram também mencionados por Silva \& Alves (1999) no gênero Pilosocereus Byles \& Rowley os quais, segundo estes autores, ampliam o volume de células especializadas no armazenamento de água. Para espécies da caatinga, como as aqui analisadas, este caracter pode ser interpretado como uma adaptação à escassa disponibilidade de água.

Nos cladódios dos indivíduos analisados, a epiderme pode apresentar aspecto plano (Tacinga inamoena (Schumann) Taylor \& Stuppy; Harrisia adscendens (Gürke) Britton \& Rose e Melocactus (L.) Link \& Otto) ou ondulado (Tacinga palmadora (Britton \& Rose) Taylor \& Stuppy), conforme já verificado na literatura para outras espécies de Cactaceae (Metcalfe \& Chalk 1950, Gibson \& Nobel 1986, Fahn \& Cutler 1992). Os estômatos observados em $H$. adscendens, M. $\times$ horridus e M. zehntneri são do tipo paralelocítico, freqüentemente observado em representantes da família e em especial na subfamília Cactoideae (Eggli 1984, Gibson \& Nobel 1986, Soffiatti \& Angyallossy 2003). Segundo Eggli (1984) o tipo de estômato ocorrente no cladódio das Opuntioideae, da qual Tacinga faz parte, é bastante diferente, denominado de "opuntioide". Porém observações feitas nos indivíduos de Tacinga analisados neste trabalho mostraram que os estômatos assemelham-se ao tipo hexacítico, descrito por FrynsClaessens \& Van-Cotthem (1973) para outros grupos de plantas.

O tipo de espinho observado nos indivíduos de Tacinga é semelhante ao citado para a subfamília Opuntioideae, o qual é denominado de gloquídeo (Metcalfe \& Chalk 1950, Gibson \& Nobel 1986), que juntamente com o arilo das sementes são sinapomorfias de Opuntioideae (Gibson \& Nobel 1986). Segundo esses autores, em Cactoideae são observados espinhos com projeções celulares regulares, semelhante ao registrado no presente trabalho para os indivíduos de Melocactus.

Com relação à periderme, observada em algumas porções do cladódio de Harrisia adscendens e Tacinga palmadora, Gibson \& Nobel (1986) e Soffiatti \& Angyalossy (2003) já mencionaram essa característica em outras espécies de Cactaceae. Segundo Gibson \& Nobel (1986) a presença de periderme pode ocorrer durante uma determinada fase de vida da planta ou por algum tipo de injúria no caule. Ainda segundo os autores, mesmo que este tecido se desenvolva em grande parte do órgão, nunca o recobre totalmente, permanecendo a epiderme como principal tecido de revestimento.

O tecido subepidérmico tem recebido diferentes denominações, sendo em geral descrito como hipoderme colenquimatosa (Metcalfe \& Chalk 1950, Conde 1975, Gibson \& Nobel 1986, Darling 1989, Fahn \& Cutler 1992, Silva \& Alves 1999). Em Cipocereus minensis (Wederm.) Ritter, Soffiatti \& Angyalossy (2003) o descrevem como uma camada de células com paredes finas que podem estar lignificadas. Nos indivíduos analisados no presente trabalho, as camadas subepidérmicas estão constituídas por células colenquimáticas do tipo lamelar, em Harrisia adscendens e angular em Tacinga. Em Melocactus o espessamento das paredes das células não caracteriza nenhum dos tipos descritos na literatura. Nesse caso, prefere-se descrever essa região, também, como colênquima, mas com células apresentando lume irregular.

Tanto a epiderme como o colênquima subepidérmico das Cactaceae, além de desempenharem função de proteção para o caule, constituem regiões importantes no estudo taxonômico de representantes da família (Gibson \& Horak 1978, Gibson \& Nobel 1986). Fato este verificado no presente estudo, em que foi possível diferenciar indivíduos com base no aspecto da epiderme, e do espessamento das paredes e do lume das células subepidérmicas. Ainda com relação a estas duas camadas foi possível observar cristais prismáticos, semelhantes aos descritos por alguns autores (Gibson 1977, Gibson \& Horak 1978, Gibson \& Nobel 1986, Silva \& Alves 1999, Soffiatti \& Angyalossy 2003). Segundo Gibson \& Horak (1978), a função dos cristais nessas regiões é de promover proteção contra herbivoria, além de refletir a excessiva incidência de raios solares, evitando possíveis danos ao parênquima clorofiliano (Fahn \& Cutler 1992).

As grandes câmaras subestomáticas localizadas em toda a extensão do colênquima subepidérmico são mencionadas por alguns autores (Conde 1975, Gibson \& Horak 1978, Soffiatti \& Angyalossy 2003) e foram observadas em todos os indivíduos analisados neste trabalho. Segundo Darling (1989) e Fahn \& Cutler (1992) a localização destas câmaras assegura rápidas 
trocas gasosas logo após a abertura dos estômatos, aumentando assim a eficiência fotossintética.

Outro caráter observado neste trabalho e que é mencionado na literatura sobre anatomia de Cactaceae, diz respeito à organização da região cortical do cladódio. Para os autores (Gibson \& Nobel 1986, Mauseth \& Ross 1988, Sajeva \& Mauseth 1991, Silva \& Alves 1999), a camada mais externa - o parênquima clorofiliano - é denominada de clorênquima, e a sua eficiência no processo fotossintético está relacionada com a estrutura delgada das paredes das células e a localização dos cloroplastos. Segundo Mauseth (1999) esta camada também pode ser descrita como parênquima paliçádico, assemelhando-se ao parênquima clorofiliano das demais espécies de plantas com folhas. Já a camada mais interna do córtex das Cactaceae, é constituída por células que assumem contorno de arredondado a irregular, denominada de parênquima aqüífero. Neste trabalho, foi possível notar a nítida distinção entre o parênquima clorofiliano e o aqüífero.

Ainda no sistema fundamental do cladódio de Cactaceae, estruturas secretoras de mucilagem são mencionadas por diversos autores como um dos caracteres adaptativos desse grupo de plantas ao ambiente xérico, uma vez que a mucilagem estaria relacionada ao armazenamento de água (Metcalfe \& Chalk 1950, Gibson 1977, Gibson \& Horak 1978, Mauseth \& Ross 1988, Mauseth 1999, Silva \& Alves 1999, Soffiatti \& Angyalossy 2003). A ocorrência dessas estruturas, mencionadas por esses autores e também observadas no presente estudo, tem sido considerada como caráter útil na separação de Opuntioideae e Cactoideae, pois representantes de Cactoideae apresentam unicamente células mucilaginosas, enquanto que na outra subfamília pode haver células e canais secretores de mucilagem.

Também no sistema vascular do cladódio é possível separar representantes das duas subfamílias pela presença de feixes corticais e medulares como sinapomorfia das Cactoideae (Gibson \& Nobel 1986, Mauseth \& Sajeva 1992). Dos indivíduos estudados no presente trabalho, Melocactus e Harrisia adscendens são representantes dessa subfamília e foram os únicos a apresentarem feixes corticais e medulares.

Cilindro vascular central constituído por feixes colaterais, que circundam a região medular do órgão, como aqui registrado, tem segundo Gibson \& Horak (1978) e Mauseth (1993b), o número de feixes proporcional ao diâmetro do órgão e, conseqüentemente, de sua medula. Além do cilindro vascular central, algumas espécies podem apresentar feixes colaterais corticais e medulares proporcionalmente menores (Boke 1941, Gibson 1973, Mauseth \& Sajeva 1992, Mauseth 1989, 1993b, 1999), conforme aqui constatado em Melocactus e H. adscendens. O significado adaptativo dos feixes corticais, segundo Mauseth \& Sajeva (1992), parece estar envolvido com transporte de produtos da fotossíntese do córtex ao estelo e vice-versa, além de evitar o embolismo (interrupção da condução). Mauseth \& Sajeva (1992) assinalam, ainda, que tanto os feixes corticais como os medulares são responsáveis pelo suprimento do tecido parenquimático cortical e medular, geralmente amplo, sendo importante principalmente em cactos globosos.

O floema das Cactaceae tem sido pouco estudado. Gibson \& Nobel (1986) mencionam que, freqüentemente, o floema primário nas Cactaceae se apresenta colapsado e o secundário está constituído por elementos de tubo crivado e células parenquimáticas. Essa organização do floema foi observada nos indivíduos analisados neste trabalho. Quanto ao xilema, tem sido mais bem estudado, com vários trabalhos abordando aspectos adaptativos e diagnósticos em Cactaceae (Gibson 1973, Gibson 1977, Gibson \& Nobel 1986, Mauseth \& Plemons-Rodriguez 1998, Soffiatti \& Angyalossy 2003).

O lenho (xilema secundário) dos cladódios das Cactaceae apresenta-se constituído essencialmente por células parenquimáticas (Mauseth 1999), como observado no presente estudo em Melocactus e Tacinga. Segundo Gibson (1973) e Mauseth (1999), lenho constituído por maior proporção de células parenquimáticas é denominado lenho juvenil (não fibroso). Em outras espécies o lenho constitui-se essencialmente de células com parede secundária (fibras e elementos de vaso). Este tipo de lenho é denominado fibroso (Gibson 1973, Mauseth 1999) como registrado em $H$. adscendens. Segundo Mauseth (1993a), algumas adaptações do lenho estão relacionadas à presença de células com paredes primárias (parenquimáticas) próximas aos elementos de vaso, formando uma matriz de condução, como observado em Melocactus e Tacinga. O autor refere, ainda, que essa matriz parenquimática permite a distensão e retração do corpo da planta, dependendo da disponibilidade de água, além de impedir o embolismo. Esta característica apresentada pelo caule das Cactaceae também representa uma estratégia no acúmulo de água (Gibson \& Nobel 1986).

Com base nos resultados obtidos percebe-se nitidamente a importância dos caracteres anatômicos na diagnose genérica e específica da família Cactaceae. 
Além disto, as cactáceas estudadas neste trabalho apresentam um conjunto de caracteres adaptativos comuns à família e que possivelmente são responsáveis pelo seu sucesso em ambientes adversos, como a caatinga.

\section{Referências bibliográficas}

ANDERSON, E.F. 2001. The cactus family. Timber Press, Portland, Oxford.

ANDRADE-LIMA, D. 1960. Estudos fitogeográficos de Pernambuco. Revista Arquivo do Instituto de Pesquisa Agronômica 5:305-341.

ARECES, A. 2004. Cactaceae. In Flowering plants of the Neotropics. (N. Smith, S.A. Mori, A. Henderson, W.D. Stevenson \& S.V. Heald, eds.). Princeton and Oxford University Press, p.73-76.

ARRUDA, E.C., ALVES, M. \& MELO-DE-PINNA, GF. 2004. Elementos traqueais em cinco taxa de Cactaceae da caatinga pernambucana. Acta Botanica Brasilica 18:731-736.

BARBOSA, M., MAYO, S., CASTRO, A., FREITAS, G., PEREIRA, M., NETO, P. \& MOREIRA, H. 1996. Checklist preliminar das angiospermas. In Pesquisa botânica nordestina. Progresso e perspectivas. (E. Sampaio, S. Mayo \& M. Barbosa, eds.). Pesquisa SBB, Recife, p.253-415.

BARROSO, G., GUIMARÃES, E., ICHASO, C., COSTA, C. \& PEIXOTO, A. 1978. Sistemática das Angiospermas do Brasil, v 1. LTC/ Edusp, São Paulo.

BARTHLOTT, W. 1994. Epicuticular wax utrastructure and systematics. In Caryophyllales:

Evolution and systematics (H.D. Behnke \& T.J. Mabry, eds.). Springer-Verlag, Berlin, p.75-86.

BARTHLOTT, W. \& HUNT, D.R. 1993. Cactaceae. In The families and genera of vascular plants (K. Kubitzki, ed.). Springer-Verlag, Berlin, p.161-197.

BERLYN, G. \& MIKSCHE, J. 1976. Botanical microtechnique and cytochemistry. The Iowa State University Press, Ames.

BOKE, N. 1941. Zonation in the shoot apices of Trichocereus spachianus and Opuntia cylindrica. American Journal of Botany 28:656-664.

BRITTON, N. \& ROSE, J. 1937. The Cactaceae. Descriptions and illustrations of plants of the cactus family. 4 Volumes. Publications of the Carnegie Institute of Washington, Washington.

CONDE, L. 1975. Anatomical comparisons of five species of Opuntia (Cactaceae). Annals of the Missouri Botanical Garden 62:425-473.

DARLING, M. 1989. Epidermis and hypodermis of saguaro cactus (Cereus giganteus): Anatomy and spectral properties. Amarican Journal of Botany 76:1698-1706.
EGGLI, U. 1984. Stomatal types of Cactaceae. Plant Systematics and Evolution 146:197-214.

FAHN, A. \& CUTLER, D. 1992. Xerophytes. Gebruder Borntraeger, Berlin.

FIAM. 1994. Perfil Municipal do Interior de Pernambuco. Fundação de Desenvolvimento Municipal do Interior de Pernambuco, Recife.

FRANKLIN, G. 1945. Preparation of thin sections of synthetic resins and wood - resin composites and a new macerating method for wood. Nature 155:51.

FRYNS-CLAESSENS, E. \& VAN-COTTHEM, W. 1973. Anew classification of the ontogenetic types of stomata. The Botanical Review 39:71-138.

GIBSON, A. 1973. Comparative anatomy of secundary xylem in Cactoideae (Cactaceae). Biotropica 5:29-65.

GIBSON, A. 1977. Wood anatomy of opuntias with cylindrical to globular stems. Botanical Gazette 138:334-351.

GIBSON, A. \& HORAK, K. 1978. Systematic anatomy and phylogeny of Mexican cacti. Annals of the Missouri Botanical Garden 65:999-1057.

GIBSON, A. \& NOBEL, P. 1986. The cactus primer. Havard University Press, Cambrigde.

JOHANSEN, D. 1940. Plant microtechnique. McGraw, New York.

KRAUS, J.E., SOUSA, H.C., REZENDE, M.H., CASTRO, N.M., VECCHI, C. \& LUQUE, R. 1998. Astra blue and basic fucsin double staining of plant materials. Biotechnic \& Histochemistry 73:235-243.

HUNT, D. \& TAYLOR, N. 1990. The genera of Cactaceae Progress Toward Consensus. Bradleya 8:85-107.

MAUSETH, J. 1989. Comparative structure-function studies within a strongly dimorphic plant, Melocactus inortus (Cactaceae). Bradleya 7:1-12.

MAUSETH, J. 1993a. Water-storing and cavitationpreventing adaptations in wood of Cacti. Annals of Botany 72:81-89.

MAUSETH, J. 1993b. Medulary bundles and the evolution of cacti. American Journal of Botany 80:928-932.

MAUSETH, J. 1999. Comparative anatomy of Espostoa, Pseudoespostoa, Thrixanthocereus and Vatricania. Bradleya 17:27-37.

MAUSETH, J. \& PLEMONS-RODRIGUEZ, B. 1998. Evolution of extreme xeromorphic characteres in woody a study of nine evolutionary lines in Cactaceae. American Journal of Botany 85:209-218.

MAUSETH, J. \& ROSS, R. 1988. Systematic anatomy of the primitive cereoid cactus Leptocereus quadricostatus. Bradleya 6:49-64.

MAUSETH, J. \& SAJEVA, M. 1992. Cortical bundles in the persistent, photosynthetic stems of cacti. Annals of Botany 70:317-324.

METCALFE, C. \& CHALK, L. 1950. Anatomy of the Dicotyledons. v. 2. Claredon Press, Oxford.

PURVIS, M., COLLIER, D. \& WALLS, D. 1964. Laboratory techniques in botany. Butterworths, London. 
RIZZINI, C. 1987. Cactáceas: Os segredos da sobrevivência. Ciência Hoje 30:30-39.

ROCHA, E. \& AGRA, M. 2002. Flora do Pico do Jabre, Paraíba, Brasil: Cactaceae Juss. Acta Botanica Brasilica 16:15-21.

SAJEVA, M. \& MAUSETH, J. 1991. Leaf-like structure in the photosynthetic, succulent stems of cacti. Annals of Botany 68:405-411.

SASS, J. 1951. Botanical microtechnique. The Iowa State College Press, Ames.

SILVA, D. \& ALVES, J. 1999. Anatomia dos órgãos vegetativos de espécies de Pilosocereus Byles \& Rowley (Cactaceae). Boletim de Botânica da Universidade de São Paulo 18:53-60.
SILVEIRA, M. 1989. Preparo de amostras biológicas para microscopia eletrônica de varredura. In Manual sobre técnicas básicas em microscopia eletrônica. v.1. (W. Souza, ed.). Sociedade Brasileira de Microscopia Eletrônica, Rio de Janeiro, p.71-79.

SOFFIATTI, P. \& ANGYALOSSY, V. 2003. Stem anatomy of Cipocereus (Cactaceae). Bradleya 21:39-48.

TAYLOR, N.P. 2000. Cactaceae of Eastern Brazil. PhD thesis, Royal Botanic Gardens, Kew.

ZAPPI, D. 1994. Pilosocereus (Cactaceae) - The genus in Brazil. Royal Botanic Gardens, Kew. 